\title{
Core-Shell C@Sb Nanoparticles as a Nucleation Layer for High-Performance Sodium Metal Anodes
}

Guanyao Wang, ${ }^{\dagger}$ Ying Zhang, ${ }^{\dagger}$ Bingkun Guo, ${ }^{\ddagger}$ Liang Tang, ${ }^{\dagger}$ Gang $X u,{ }^{\dagger}$ Yuanjun Zhang, ${ }^{\dagger}$ Minghong Wu, ${ }^{* \dagger}$ Hua-Kun Liu, ${ }^{\S}$ Shi-Xue Dou, ${ }^{\S}$ and Chao $W u^{*}, ;, \S$

${ }^{\dagger}$ School of Environmental and Chemical Engineering and ${ }^{\dagger}$ Materials Genome Institute, Shanghai University, Shanghai 200444, China

${ }^{\S}$ Institute for Superconducting \& Electronic Materials, Australian Institute of Innovative Materials, University of Wollongong, NSW 2522, Australia 


\section{Experimental Section}

Materials: $\mathrm{FeCl}_{3} \cdot 6 \mathrm{H}_{2} \mathrm{O}$ (Greagent, $\geq 99.0 \%$ ), trisodium citrate (Adamas, $>98 \%$ ), sodium acetate (Greagent, $\geq 99.0 \%$ ), ethylene glycol (Adamas, >99\%), resorcinol (Adamas, >99\%) formaldehyde (Adamas, 37-40 wt\% in water), antimony trichloride (Adamas, >99\%) and other common solvents were supplied by Tansoole (China). Antimony powder (200 mesh, 99.5\% metals basis) was provided by Alfa Aesar (Thermo Fisher Scientific). Ammonium hydroxide aqueous solution (28 wt\%) were purchased from Sinopharm Chemical Reagent Co., Ltd. (China). Sodium cubes stored in mineral oil were obtained from Sigma-Aldrich. Sodium trifluoromethanesulfonate $\left(\mathrm{NaSO}_{3} \mathrm{CF}_{3},>99.8 \%\right)$, diethylene glycol dimethyl ether (diglyme, $>99.9 \%$ ), propylene carbonate (PC, >99.98\%), and fluoroethylene carbonate (FEC, >99.95\%) were all battery grade and purchased from DoDoChem (China). $\mathrm{NaClO}_{4}$ (battery grade) was supplied by Shanghai Songjing New Energy Technology (China). Polypropylene separator (Celgard 3501) was purchased from Celgard Inc.

Synthesis of $\mathrm{Fe}_{3} \mathrm{O}_{4}$ Nanoparticles (NPs): The $\mathrm{Fe}_{3} \mathrm{O}_{4}$ NPs with a diameter of about $200 \mathrm{~nm}$ were prepared according to previous literature. ${ }^{\mathrm{S} 1}$ Typical, $\mathrm{FeCl}_{3} \cdot 6 \mathrm{H}_{2} \mathrm{O}(2.433 \mathrm{~g}, 9 \mathrm{mmol})$, trisodium citrate $(0.774 \mathrm{~g}, 3 \mathrm{mmol})$, and sodium acetate $(3.6 \mathrm{~g}, 43.8 \mathrm{mmol})$ were dissolved in ethylene glycol $(60 \mathrm{~mL})$ by stirring for $2 \mathrm{~h}$. The obtained solution was then sealed in a Teflon-lined stainless-steel autoclave and heated at $200^{\circ} \mathrm{C}$ for $10 \mathrm{~h}$. The resulting products were isolated by centrifugation and then washed with deionized water and ethanol for three time, respectively.

Synthesis of core-shell C@Fe NPs: $0.5 \mathrm{~g} \mathrm{Fe}_{3} \mathrm{O}_{4}$ NPs were firstly dispersed in a solution containing $100 \mathrm{~mL}$ ethanol, $50 \mathrm{~mL}$ distilled water, and $3 \mathrm{~mL}$ concentrated ammonia solution (28 wt $\%$ ) under ultrasound for $30 \mathrm{~min}$. Then, $0.5 \mathrm{~g}$ resorcinol and $0.45 \mathrm{~mL}$ formaldehyde (37-40 wt $\%$ ) were added into the solution, and stirred for another $12 \mathrm{~h}$. After polymerization, the 
obtained core-shell $\mathrm{RF} @ \mathrm{Fe}_{3} \mathrm{O}_{4} \mathrm{NPs}$ were washed with deionized water and ethanol for three times, respectively. The obtained RF@ $\mathrm{Fe}_{3} \mathrm{O}_{4} \mathrm{NPs}$ were calcined at $600^{\circ} \mathrm{C}$ for $5 \mathrm{~h}$ with a ramp of $2{ }^{\circ} \mathrm{C} / \mathrm{min}$ under the atmosphere of $\mathrm{Ar} / \mathrm{H}_{2}$ to get the core-shell C@ $@ \mathrm{Fe}$ NPs.

Synthesis of C@Sb NPs: $0.1 \mathrm{~g} \mathrm{C@Fe} \mathrm{NPs} \mathrm{and} 1.5 \mathrm{~g} \mathrm{SbCl}_{3}$ were firstly added into $60 \mathrm{~mL}$ ethanol solution. The solution was then sealed into the Teflon-lined stainless-steel autoclave and heated at $60{ }^{\circ} \mathrm{C}$ for $10 \mathrm{~h}$. The desired C@Sb NPs were collected by filtration without further purification. According to the weight of calcined product of $\mathrm{C} @ \mathrm{Sb}$ in air, the weight ratio of $\mathrm{Sb}$ in the proposed C@Sb was about $82 \%$.

Synthesis of hollow carbon spheres (HCSs): The obtained C@Fe NPs were dispersed and stirred in $4 \mathrm{M} \mathrm{HCl}$ aqueous solution for $24 \mathrm{~h}$ to etch the inner Fe particles. HCSs were collected by centrifugation and then washed with deionized water and ethanol for three time, respectively.

Electrochemical measurement: All the electrochemical testing was performed in CR2032 coin cells at room temperature. The cells were assembled/disassembled in an argon-filled glovebox (MIKROUNA, $\mathrm{O}_{2}$ and $\mathrm{H}_{2} \mathrm{O}<0.01 \mathrm{ppm}$ ). Half-cell testing was carried out by using bare $\mathrm{Cu}$, HCS@Cu, or Sb@Cu, C@Sb@Cu foils (as working electrodes) and polished Na foils (as the counter and reference electrodes). The diameters of these working electrodes and Na foils are 10 and $12 \mathrm{~mm}$, respectively. Nucleation buffer layers were made by casting the slurry mixture containing active materials (80 wt $\%)$, Super P (10 wt \%), and polyvinylidene fluoride (PVDF, 10 $\mathrm{wt} \%$ ) binder on $\mathrm{Cu}$ foils. The mass loading of active materials was lied in the range of $1-2 \mathrm{mg}$ $\mathrm{cm}^{-2}$. The symmetric cells were assembled by using freshly deposited sodium on bare $\mathrm{Cu}$, $\mathrm{HCS} @ \mathrm{Cu}$ or $\mathrm{C} @ \mathrm{Sb} @ \mathrm{Cu}$ foils on each side.1.0 $\mathrm{M} \mathrm{NaSO}_{3} \mathrm{CF}_{3}$ in diglyme without any additional additives was used as electrolyte for half cells and symmetric cells (35 $\mu \mathrm{L}$ for each cell). Polypropylene (Celgard 3501) was used as the separator for half cells and symmetric cells. The 
cut-off voltage of cells is fixed at $0.3 \mathrm{~V}$ in the above experiments to alleviate the fading of $\mathrm{Na}-$ $\mathrm{Sb}$ alloy interphase and ensure the stability of alloyed buffer layer during the repeated plating/stripping process. For the plating/stripping testing, all the cells were initially galvanostatically cycled at $0.1 \mathrm{~mA} \mathrm{~cm}$-2 for 5 times. $\mathrm{Na}_{3} \mathrm{~V}_{2}\left(\mathrm{PO}_{4}\right)_{3}$ was synthesized according to previous literature. ${ }^{\mathrm{S} 2}$ The $\mathrm{Na}_{3} \mathrm{~V}_{2}\left(\mathrm{PO}_{4}\right)_{3}$ cathode was prepared by casting the slurry mixture of active materials, Super P, and PVDF binder with a mass ratio of 80:10:10 on Al foils. A Whatman glass fiber was used as the separator for full cell. The electrolyte for full cells was $1 \mathrm{M}$ $\mathrm{NaClO}_{4}$ in PC with $5 \mathrm{wt} \% \mathrm{FEC}(80 \mu \mathrm{L}$ for each cell). The mass loading of active materials was $\sim 2 \mathrm{mg} \mathrm{cm}^{-2}$. All the battery tests were performed on a NEWARE CT-4000 test system at room temperature.

Characterization: X-ray diffraction (XRD) was performed on Rigaku D/MAX 2200V PC. The morphology and microstructure of materials and deposited sodium were investigated by a field emission scanning electron microscopy (FE-SEM, Hitachi, Regulus 8230) and a transmission electron microscopy (TEM, JEOL, JEM-2100F). The samples containing sodium were transferred into SEM chamber by using a protection box filled with argon to avoid air contact. 

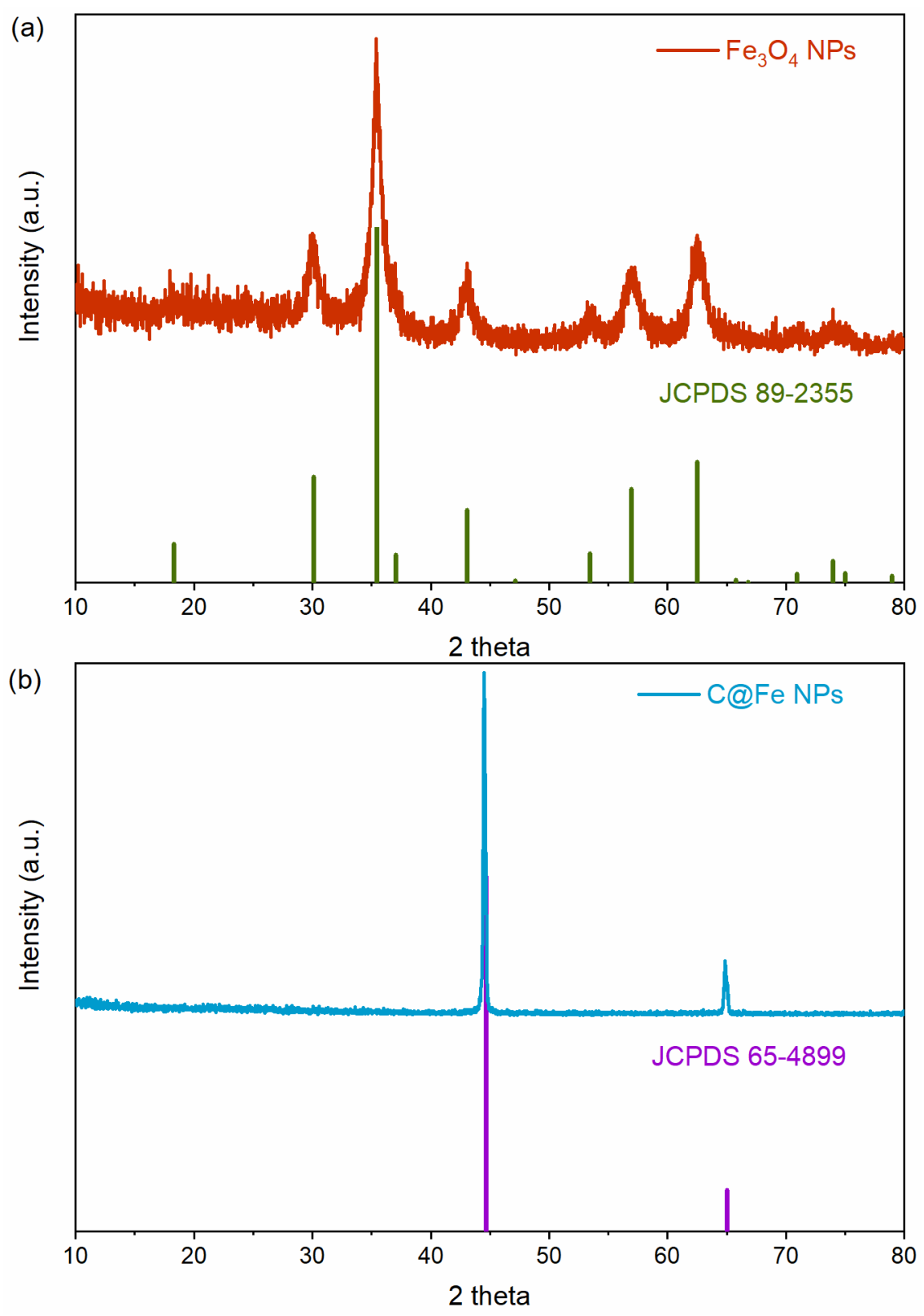

Figure S1. XRD patterns of $\mathrm{Fe}_{3} \mathrm{O}_{4}$ and core-shell C@ $\mathrm{Fe}$ NPs. 

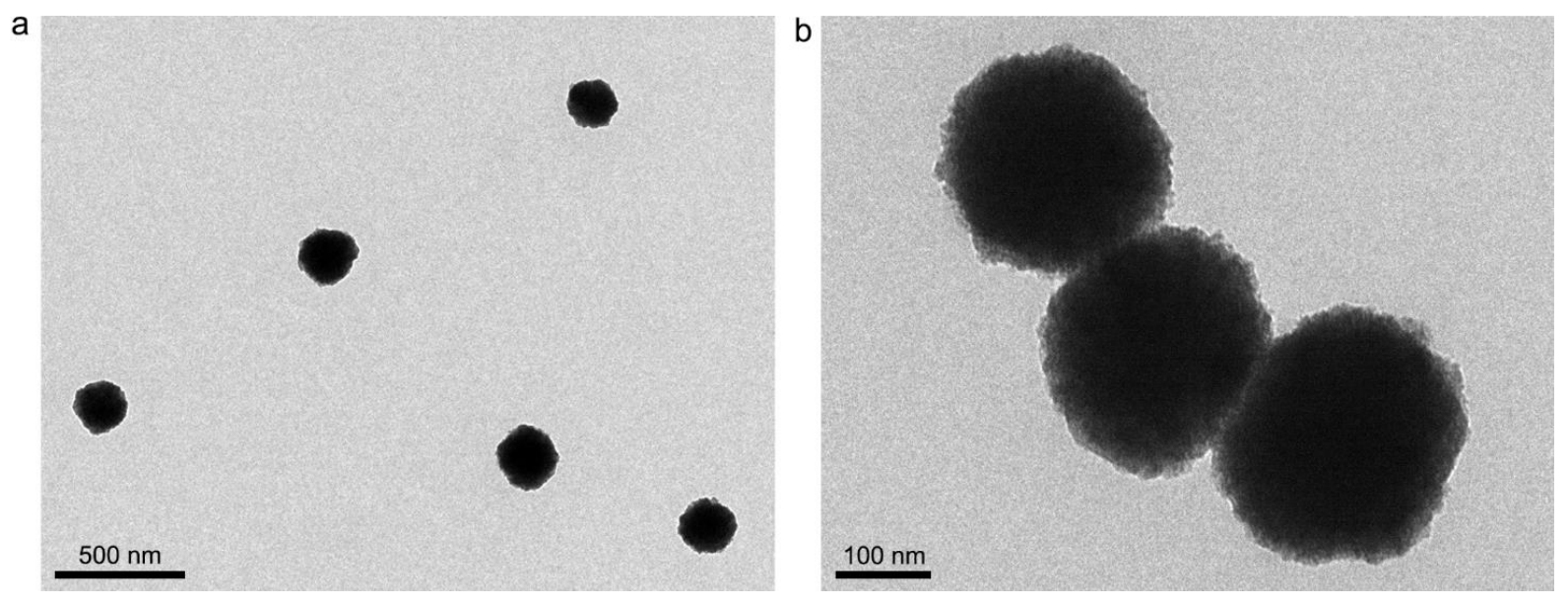

Figure S2. TEM images of $\mathrm{Fe}_{3} \mathrm{O}_{4}$ NPs. 

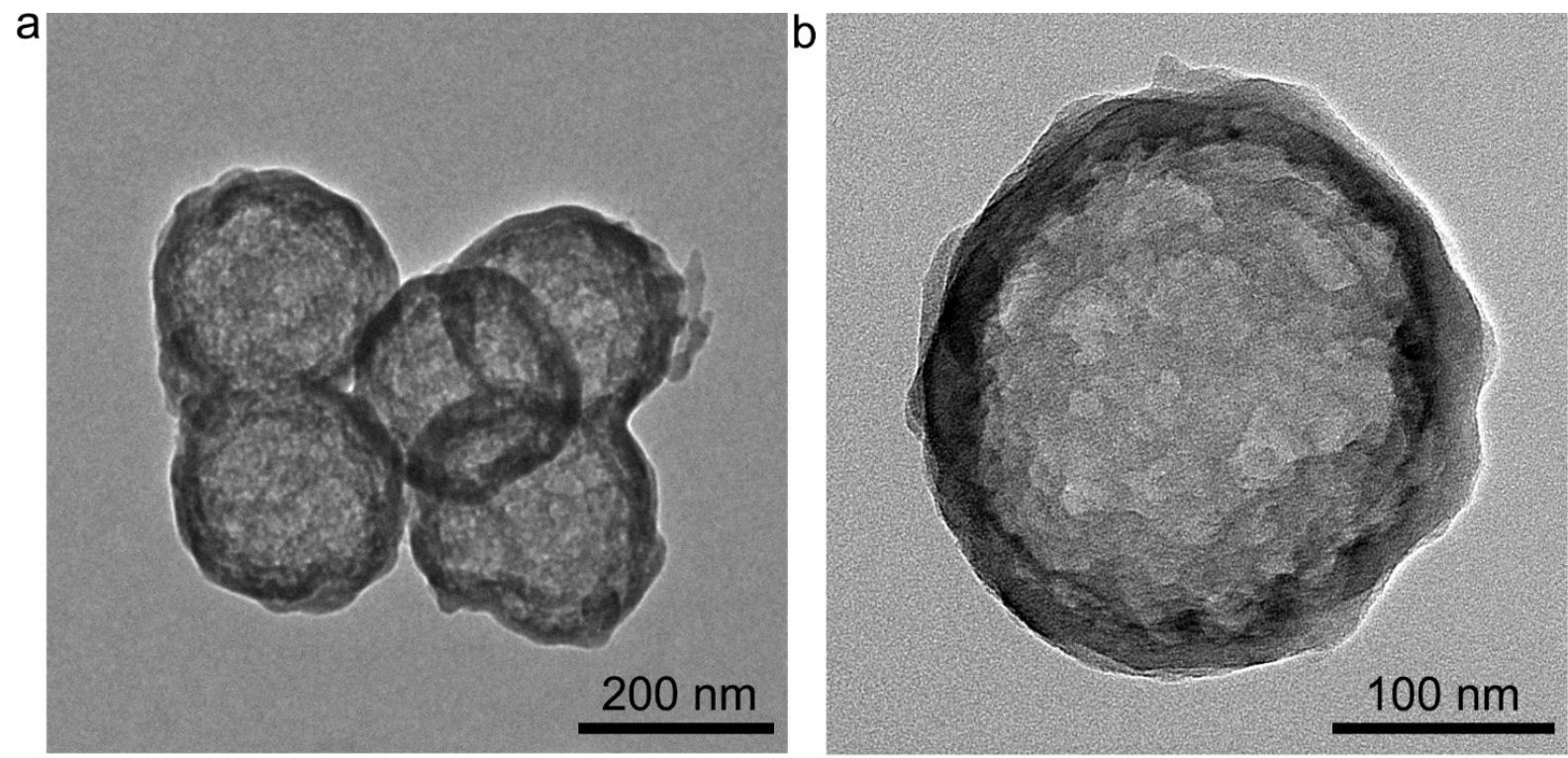

Figure S3. TEM images of HCSs. 

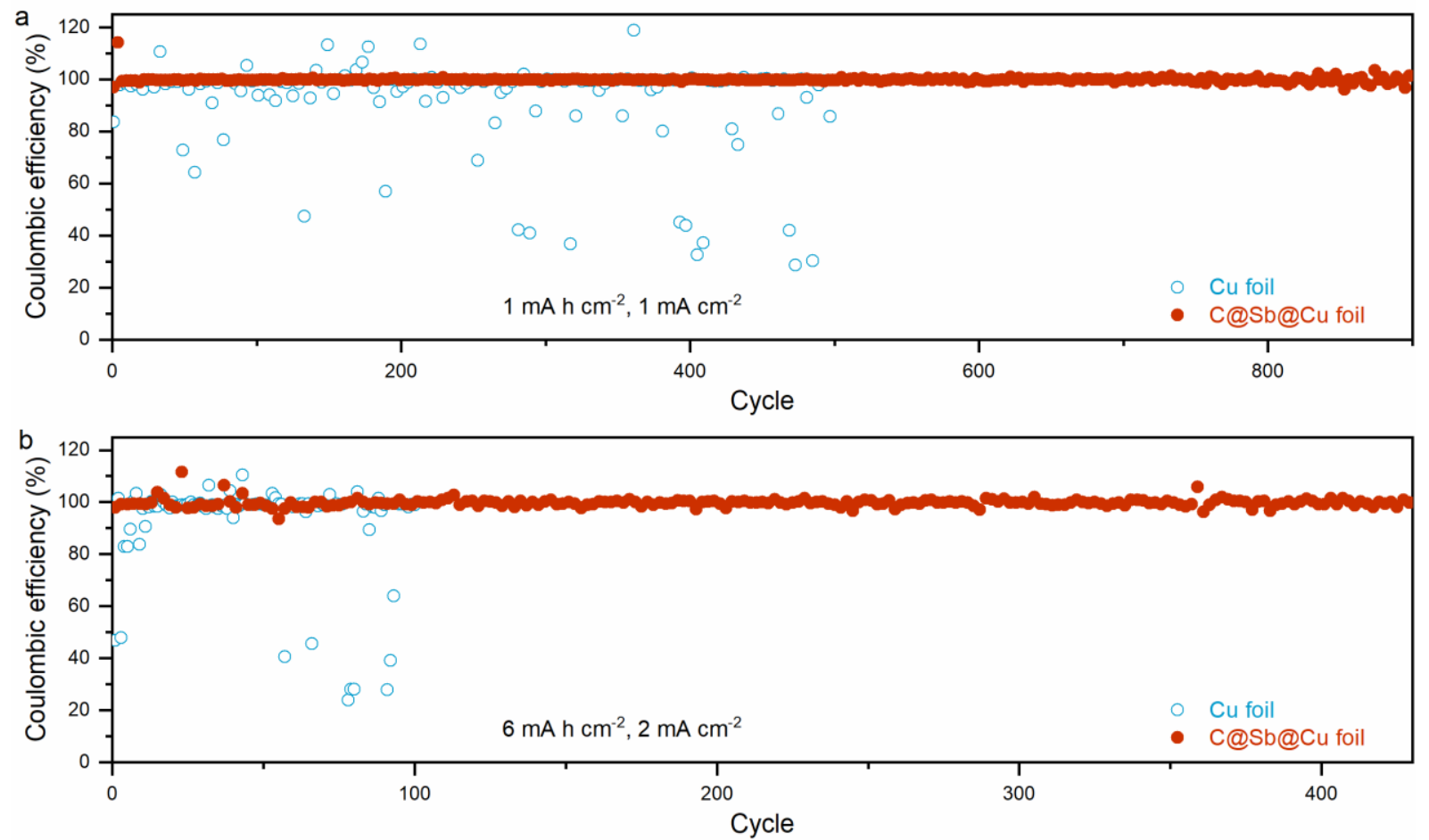

Figure S4. Coulombic efficiency of sodium plating/stripping for the cells using bare and $\mathrm{C} @ \mathrm{Sb} @ \mathrm{Cu}$ foils at a current density of (a) $1 \mathrm{~mA} \mathrm{~cm}^{-2}$ for $1 \mathrm{~h}$ and (b) $2 \mathrm{~mA} \mathrm{~cm}^{-2}$ for $3 \mathrm{~h}$. 
a

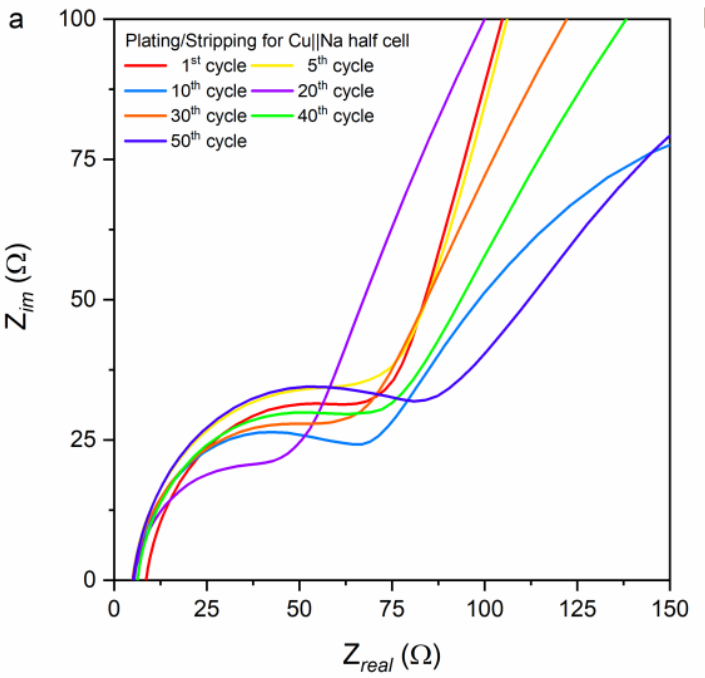

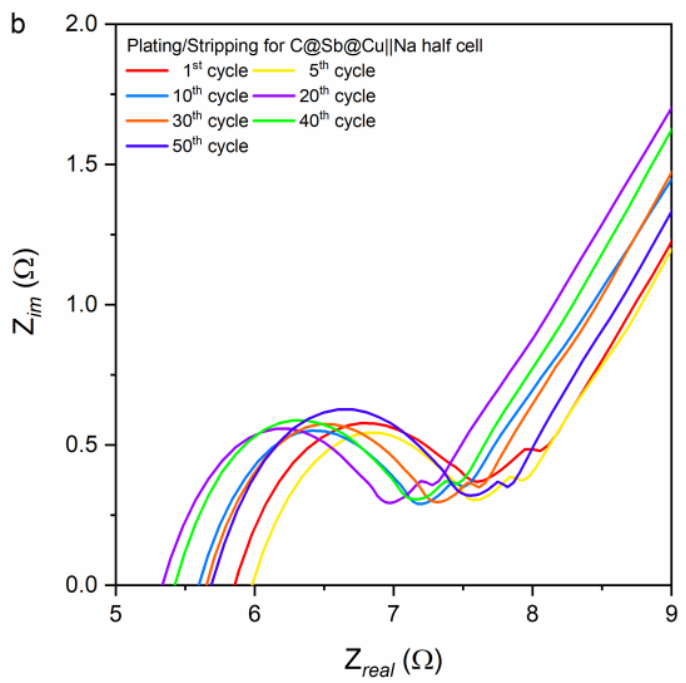

Figure S5. The electrochemical impedance spectra of (a) $\mathrm{Cu} \| \mathrm{Na}$ and (b) $\mathrm{C} @ \mathrm{Sb} @ \mathrm{Cu} \| \mathrm{Na}$ half cells after different plating/stripping cycles at $1 \mathrm{~mA} \mathrm{~cm}^{-2}$ and $1 \mathrm{~mA} \mathrm{~h} \mathrm{~cm}{ }^{-2}$. Notice that the scales of the coordinate axes are different. 


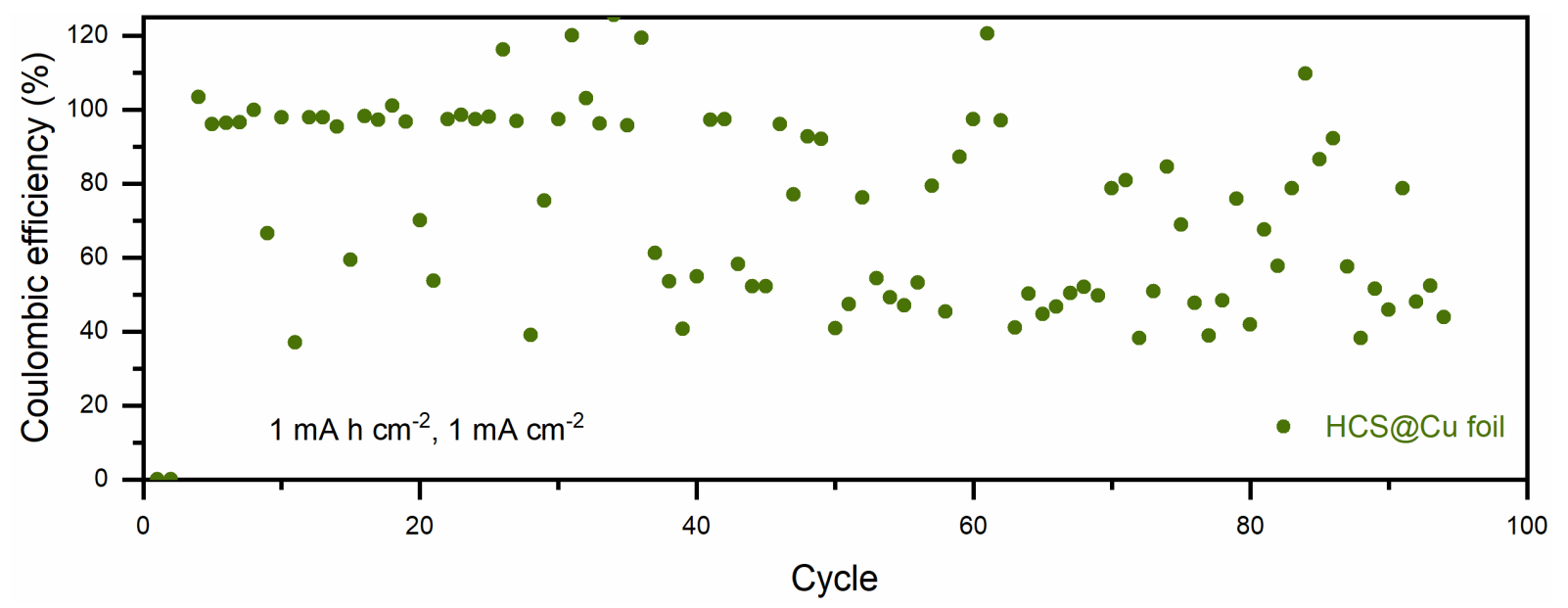

Figure S6. Coulombic efficiency of sodium plating/stripping for the cell using HCS@Cu foil at a current density of $1 \mathrm{~mA} \mathrm{~cm}{ }^{-2}$ for $1 \mathrm{~h}$. 


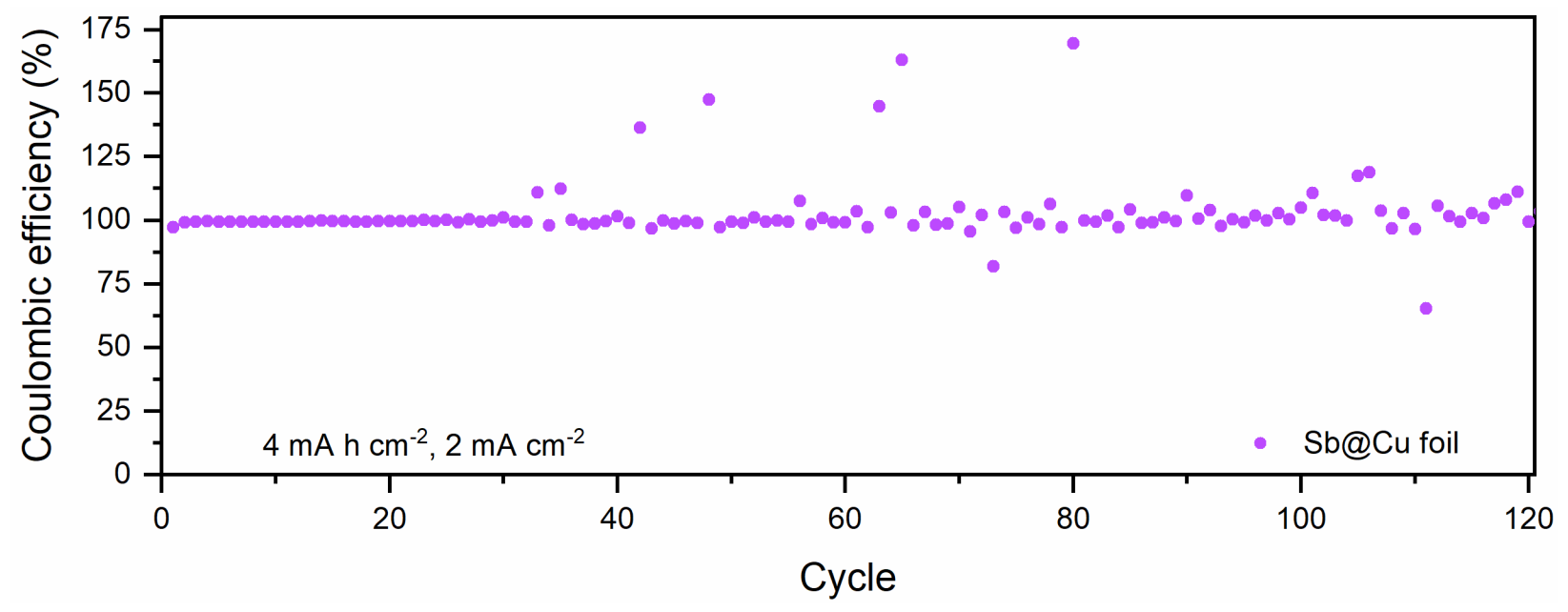

Figure S7. Coulombic efficiency of sodium plating/stripping for the cell using $\mathrm{Sb} @ \mathrm{Cu}$ foil at a current density of $2 \mathrm{~mA} \mathrm{~cm}{ }^{-2}$ for $2 \mathrm{~h}$. 


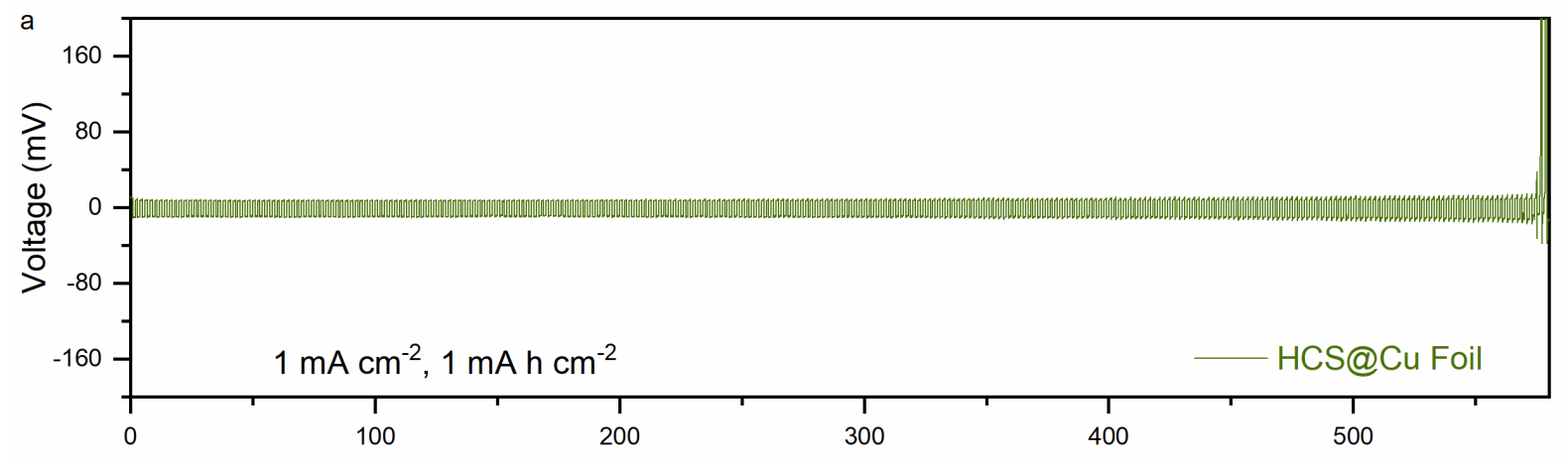

Time (h)
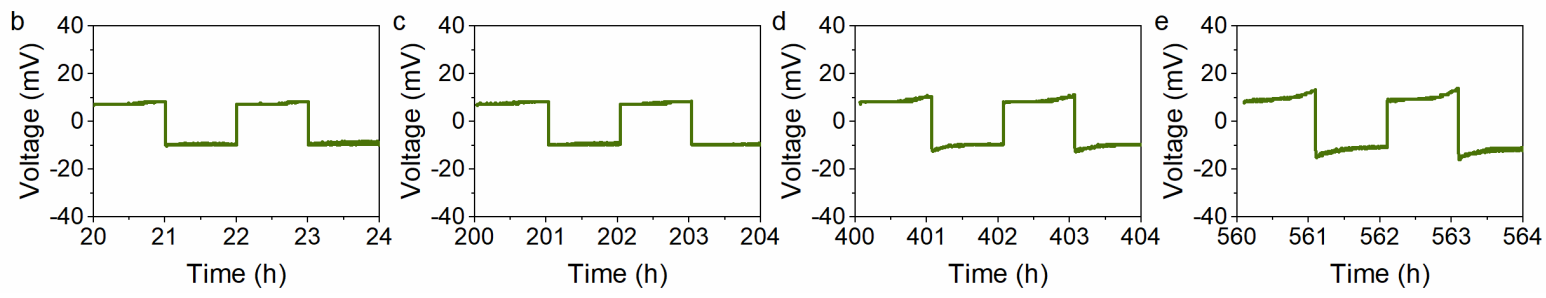

Figure S8. (a) Cycling performance of $\mathrm{Na}|| \mathrm{Na}$ symmetric cells with $\mathrm{HCS} @ \mathrm{Cu}$ foil at a current density of $1 \mathrm{~mA} \mathrm{~cm}^{-2}$ for $1 \mathrm{~h}$. Enlarged views at different cycling times: (b) 20-24 h, (c) 200$204 \mathrm{~h}$, (d) 400-404 h, and (e) 560-564 h. The areal capacity of deposited sodium on the HCS@Cu foil is $4 \mathrm{~mA} \mathrm{~h} \mathrm{~cm}^{-2}$. 

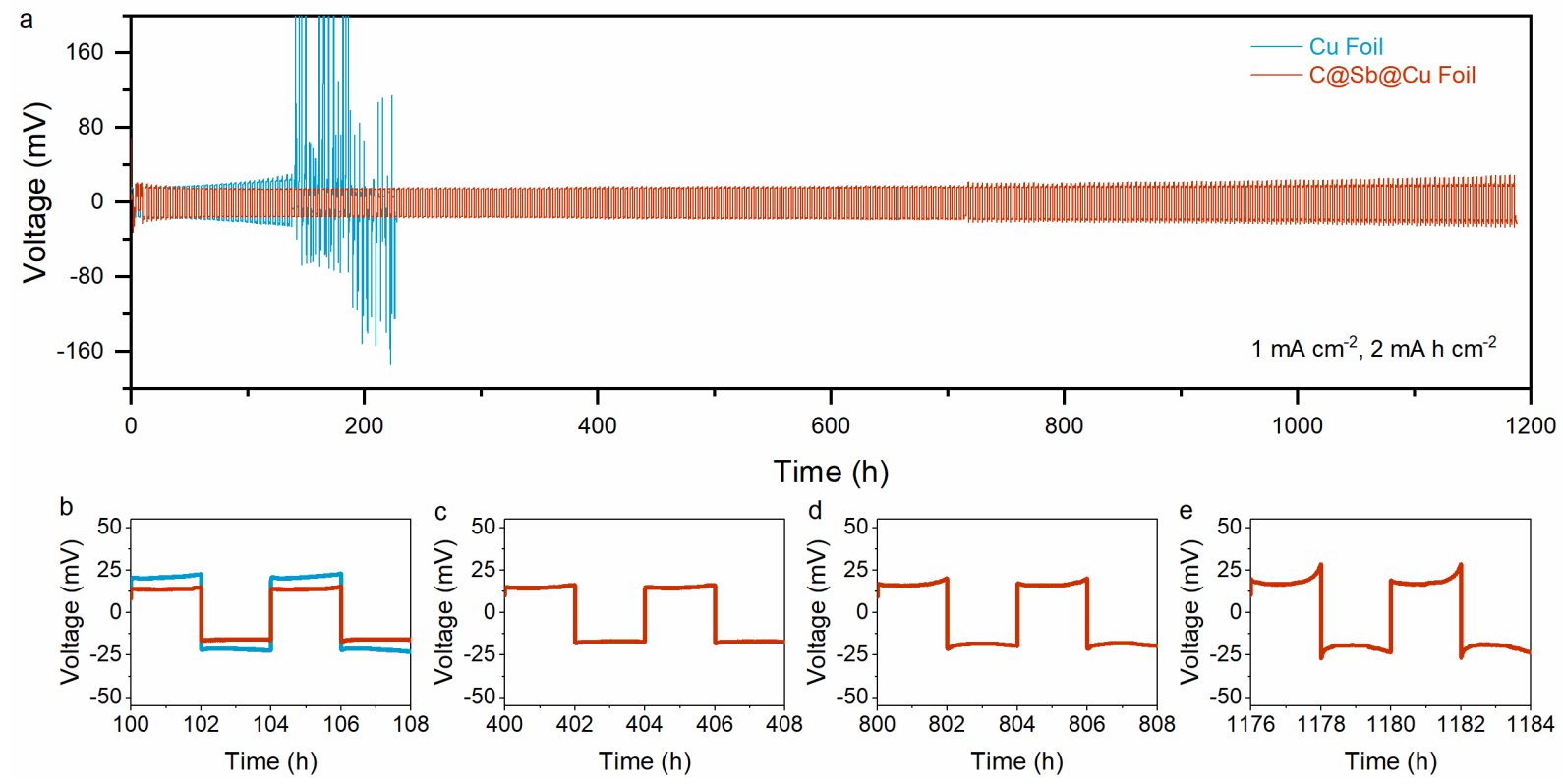

Figure S9. (a) Cycling performance of $\mathrm{Na} \| \mathrm{Na}$ symmetric cells with bare $\mathrm{Cu}$ foil and $\mathrm{C} @ \mathrm{Sb} @ \mathrm{Cu}$ foil at a current density of $1 \mathrm{~mA} \mathrm{~cm}{ }^{-2}$ for $2 \mathrm{~h}$. Enlarged views at different cycling times: (b) 100$108 \mathrm{~h}$, (c) 400-408 h, (d) 800-808 h, and (e) 1176-1184 h. The areal capacity of deposited sodium on those electrodes is $6 \mathrm{~mA} \mathrm{~h} \mathrm{~cm}$. 


\section{$2 \mu \mathrm{m}$}

Figure S10. SEM image and optical photograph (inset) of sodium metal on $\mathrm{C} @ \mathrm{Sb} @ \mathrm{Cu}$ foil disassembled from the $\mathrm{Na} \| \mathrm{Na}$ symmetric cells cycling for 100 times at a current density of $1 \mathrm{~mA}$ $\mathrm{cm}^{-2}$ and a capacity of $1 \mathrm{~mA} \mathrm{~h} \mathrm{~cm}^{-2}$. 

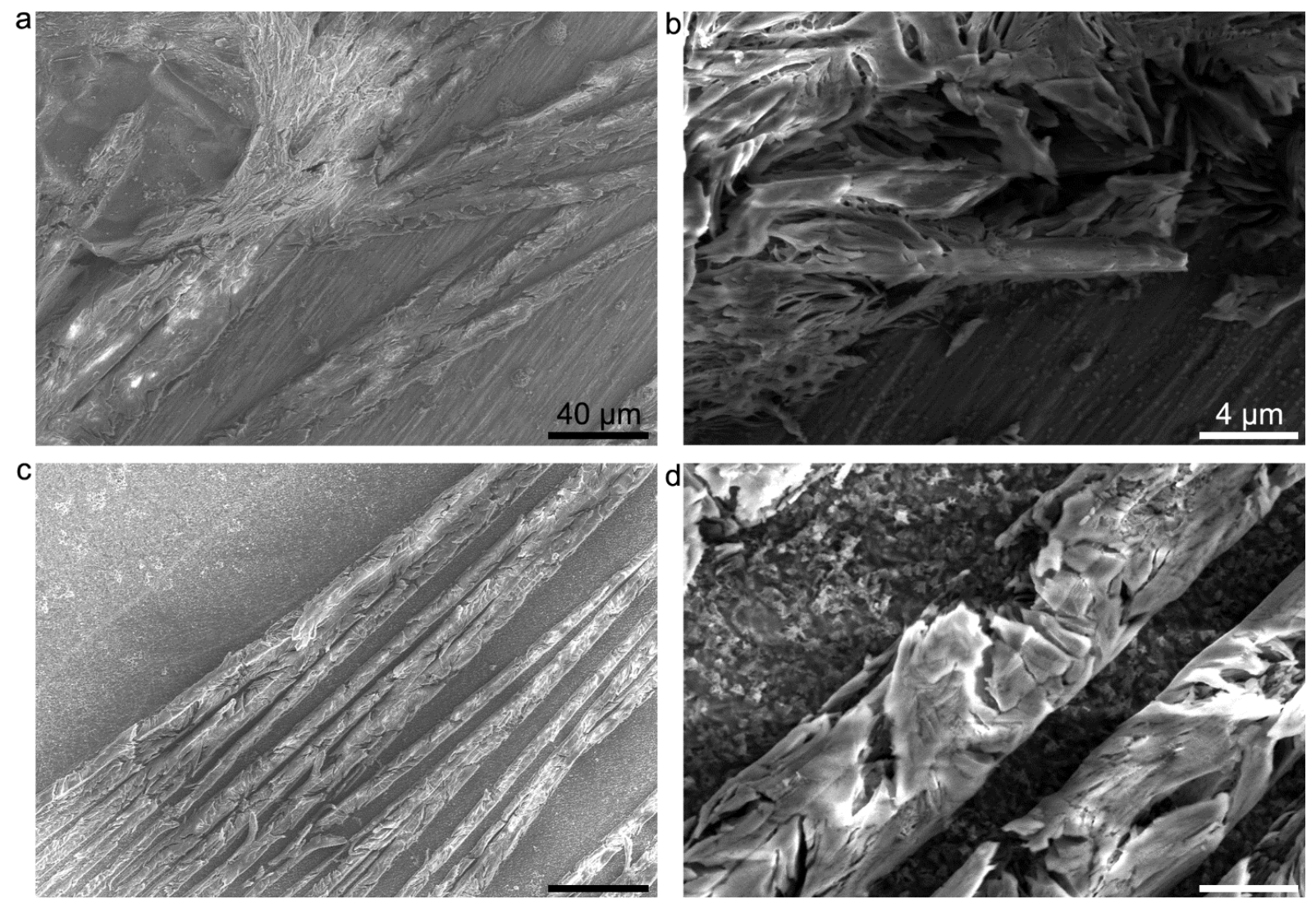

Figure S11. SEM images of $1 \mathrm{~mA} \mathrm{~h} \mathrm{~cm}^{-2}(\mathrm{a}, \mathrm{b})$ and $6 \mathrm{~mA} \mathrm{~h} \mathrm{~cm}$ (c, d) plated sodium metal on pristine $\mathrm{Cu}$ foils. The black and white scale bars are 40 and $4 \mu \mathrm{m}$, respectively. 

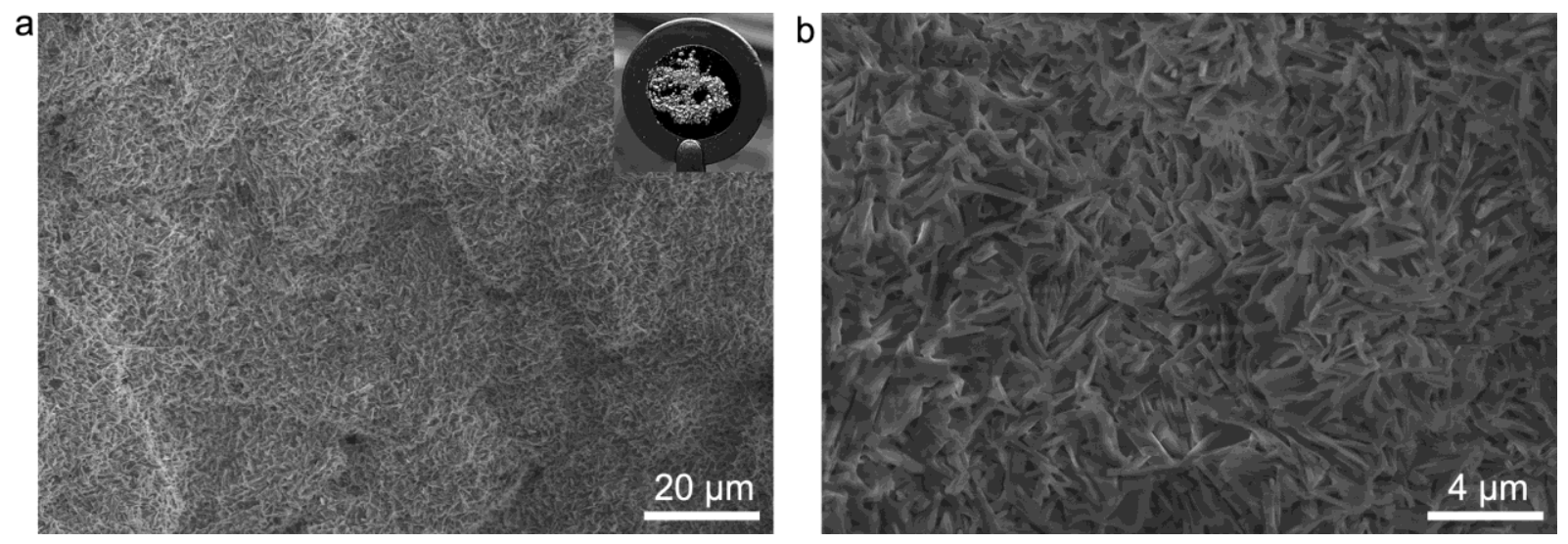

Figure S12. SEM images of $6 \mathrm{~mA} \mathrm{~h} \mathrm{~cm}^{-2}$ plated sodium metal on $\mathrm{HCS} @ \mathrm{Cu}$ foil. Inset is the corresponding optical photograph. 


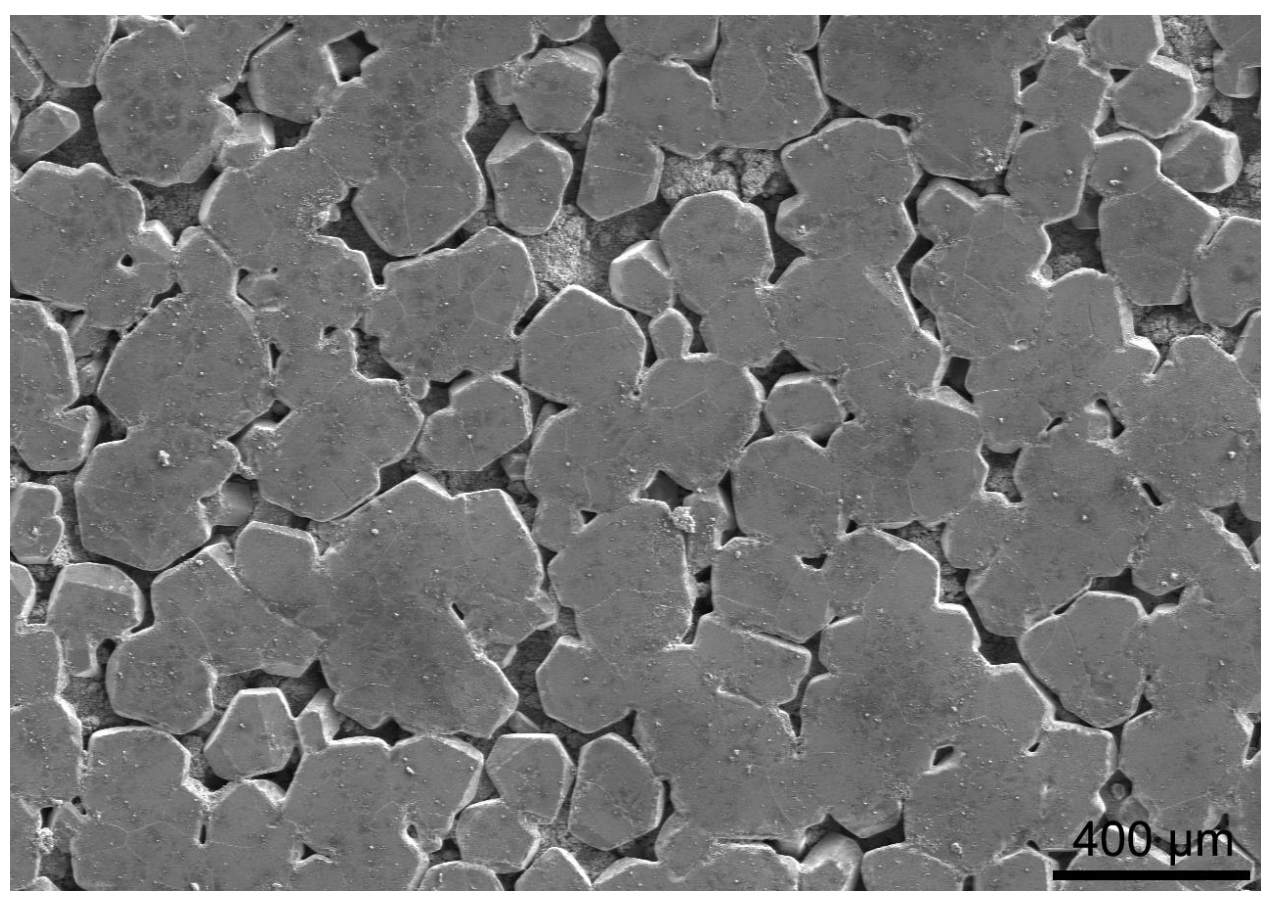

Figure S13. SEM image of $6 \mathrm{~mA} \mathrm{~h} \mathrm{~cm}^{-2}$ plated sodium metal on $\mathrm{C} @ \mathrm{Sb} @ \mathrm{Cu}$ foil. 

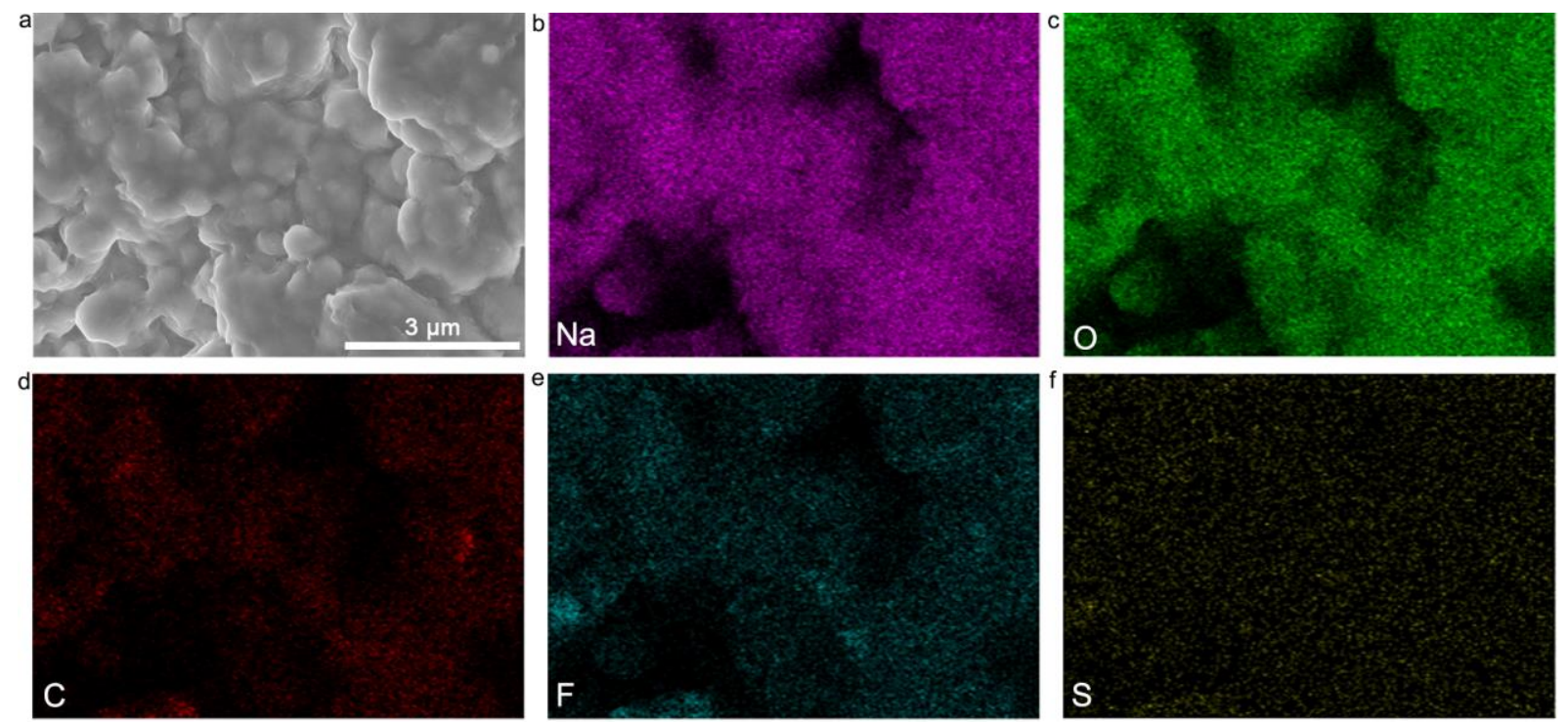

Figure S14. (a) Cross-sectional image of $1 \mathrm{~mA} \mathrm{~h} \mathrm{~cm}^{-2}$ plated sodium metal on $\mathrm{C} @ \mathrm{Sb} @ \mathrm{Cu}$ foil and (b)-(f) corresponding element mapping images. 

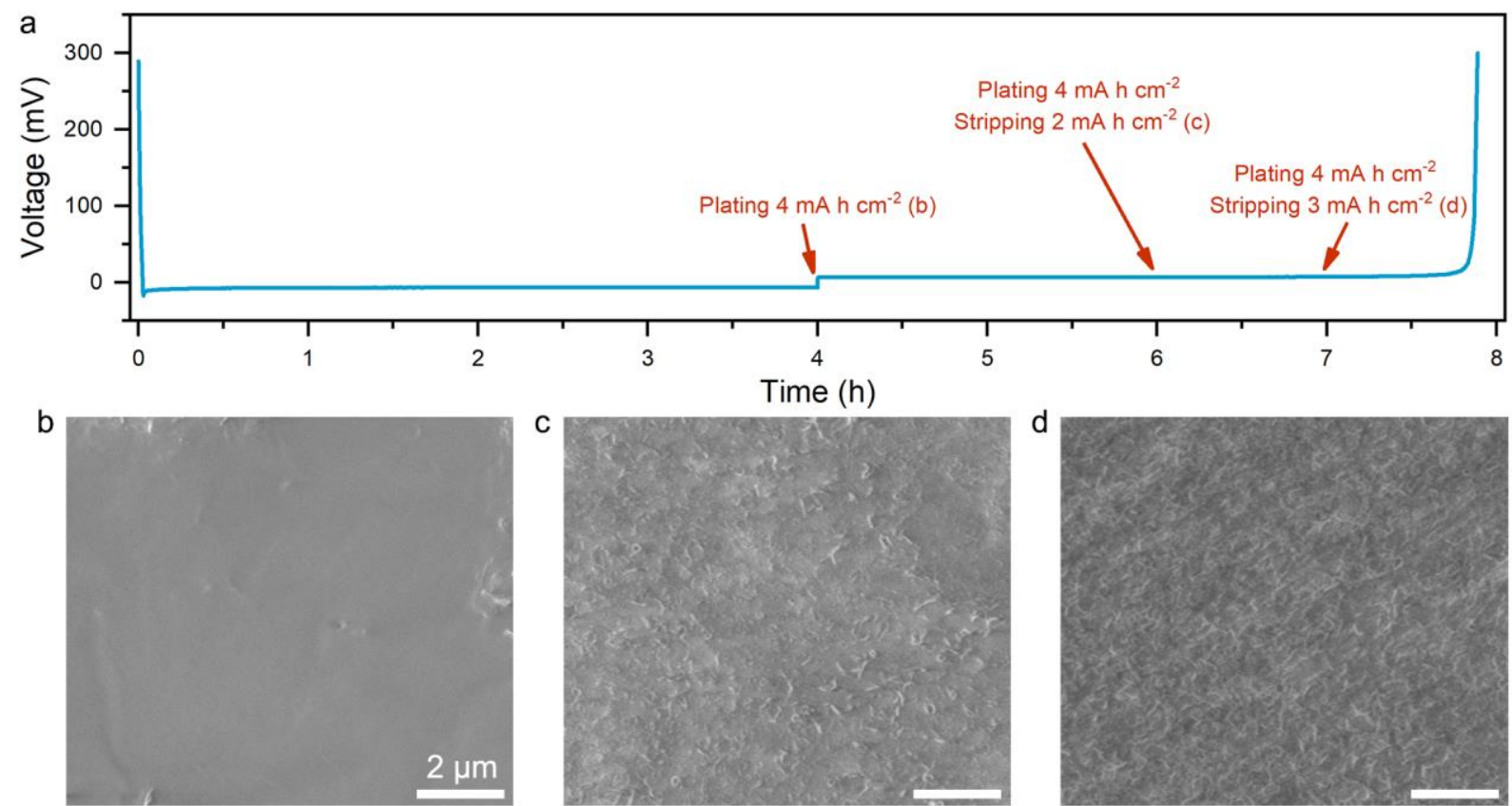

Figure S15. (a) Voltage profile of sodium plating/stripping on $\mathrm{C} @ \mathrm{Sb} @ \mathrm{Cu}$ foil at a current density of $1 \mathrm{~mA} \mathrm{~cm}^{-2}$ for $4 \mathrm{~h}$. (b)-(d) SEM images of C@ Sb NPs at different stages. 

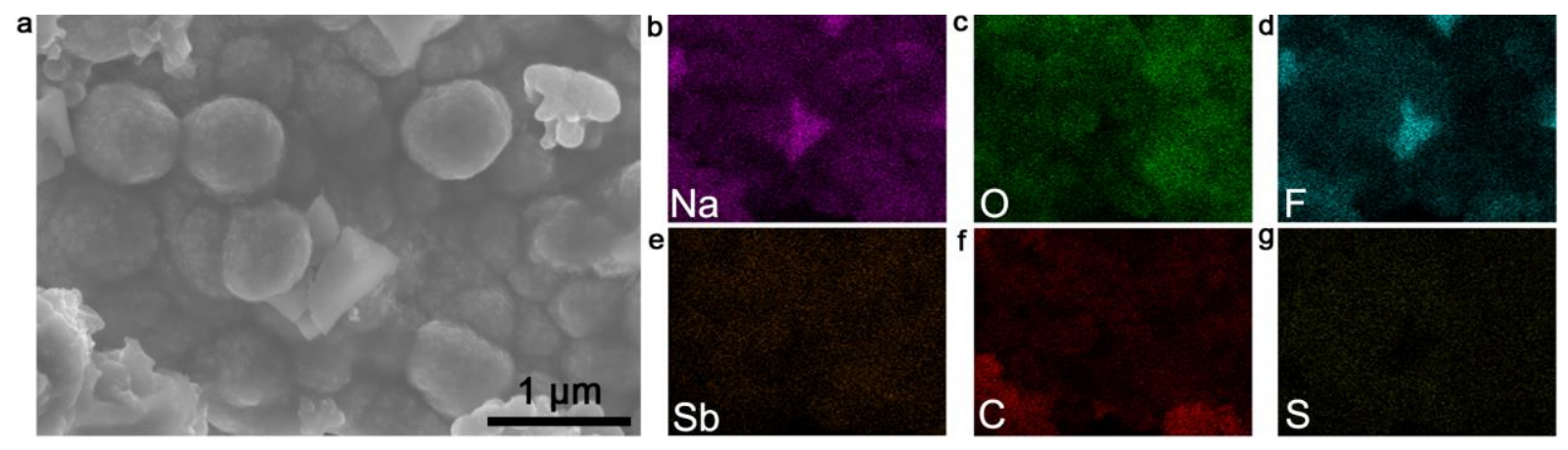

Figure S16. SEM image of C@Sb NPs after 100 plating/stripping cycles (a) and corresponding element mapping images: (b) Na, (c) O, (d) F, (e) Sb, (f) C, and (g) S. 


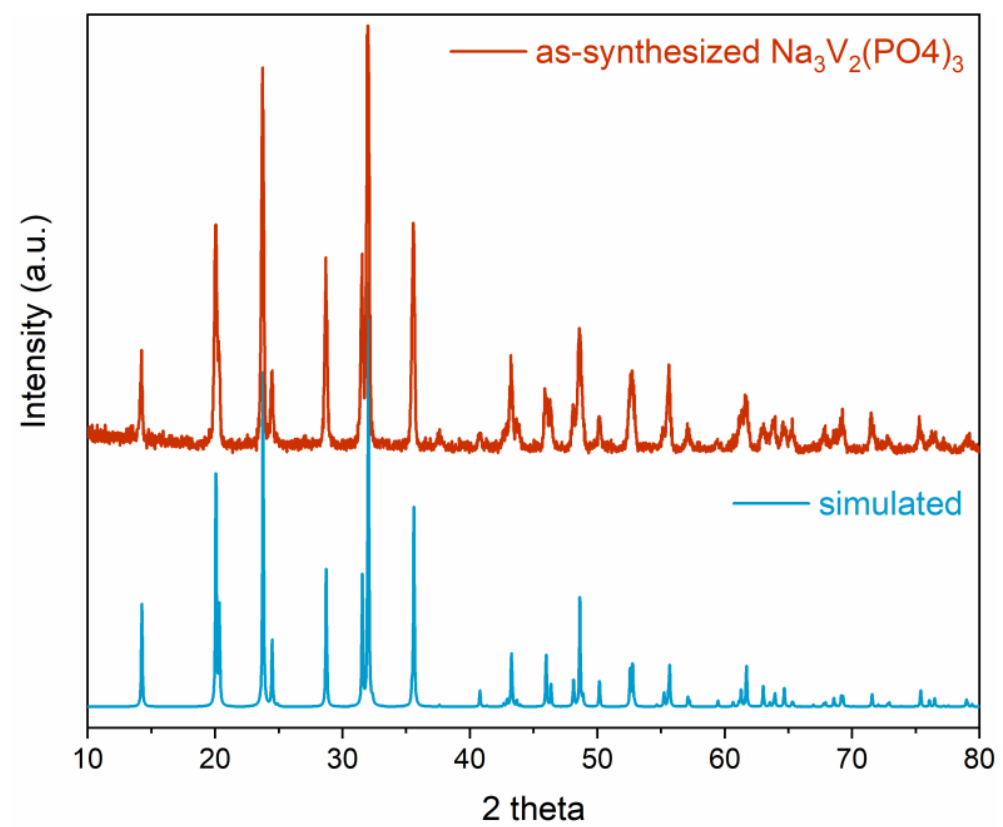

Figure S17. XRD pattern of $\mathrm{Na}_{3} \mathrm{~V}_{2}\left(\mathrm{PO}_{4}\right)_{3}$. 


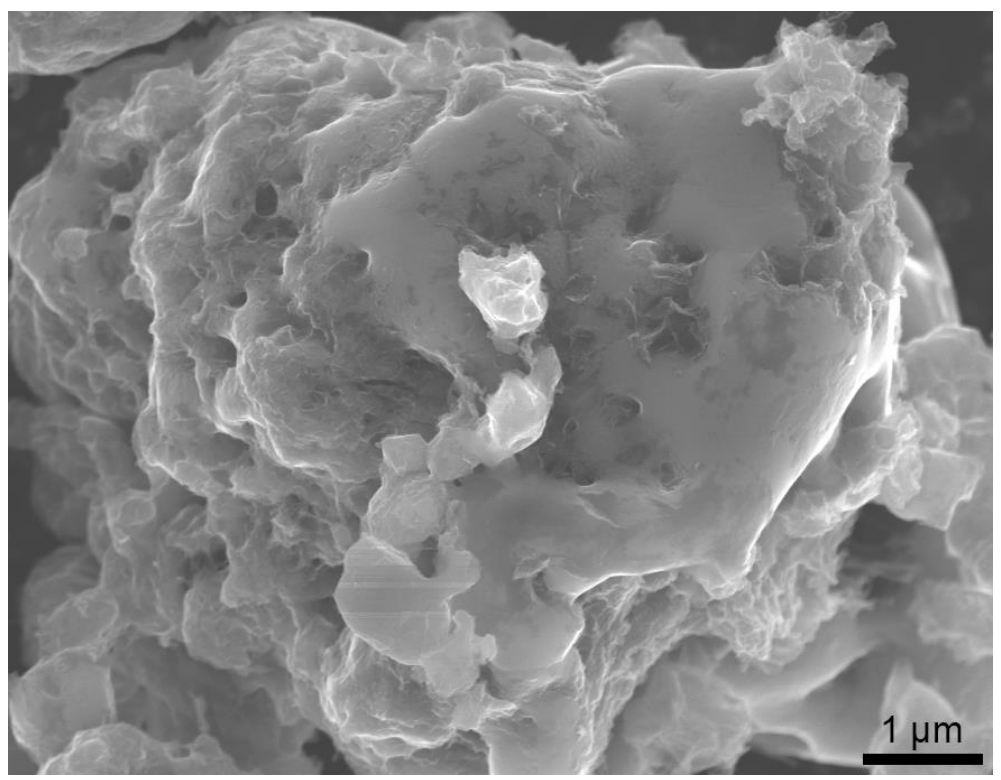

Figure S18. SEM image of $\mathrm{Na}_{3} \mathrm{~V}_{2}\left(\mathrm{PO}_{4}\right)_{3}$. 

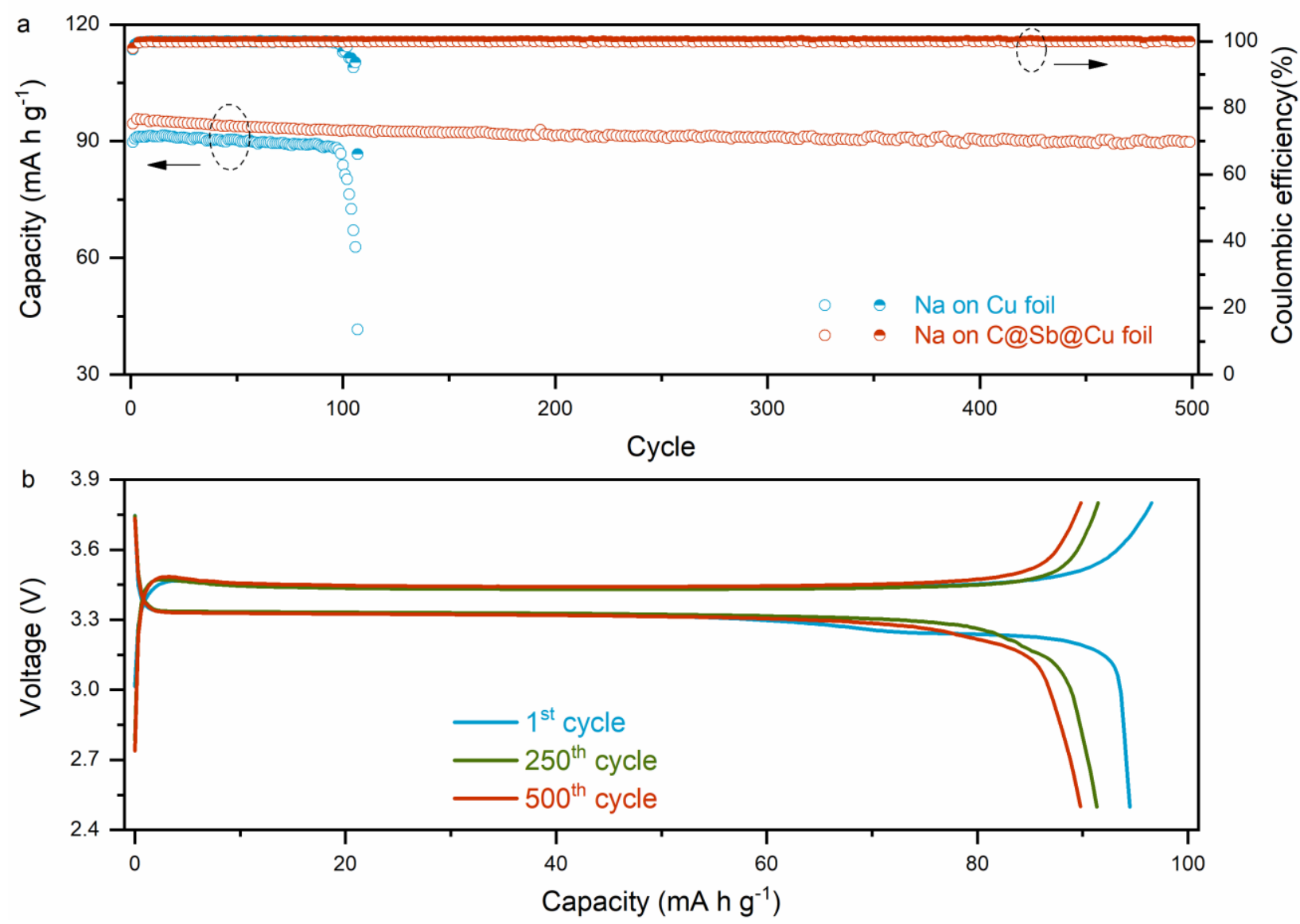

Figure S19. (a) Cycling performance of $\mathrm{Na} \| \mathrm{Na}_{3} \mathrm{~V}_{2}\left(\mathrm{PO}_{4}\right)_{3}$ full cells at $1 \mathrm{C}\left(1 \mathrm{C}=117 \mathrm{~mA} \mathrm{~g}^{-1}\right)$. (b) Selected voltage profiles of the full cell using sodium on $\mathrm{C} @ \mathrm{Sb} @ \mathrm{Cu}$ foil. The mass loading of $\mathrm{Na}_{3} \mathrm{~V}_{2}\left(\mathrm{PO}_{4}\right)_{3}$ cathode is $\sim 2 \mathrm{mg} \mathrm{cm}^{-2}$. The anode is prepared by plating $6 \mathrm{~mA} \mathrm{~h} \mathrm{~cm} \mathrm{co}^{-2}$ of sodium metal on bare or $\mathrm{C} @ \mathrm{Sb} @ \mathrm{Cu}$ foil in half cell. 

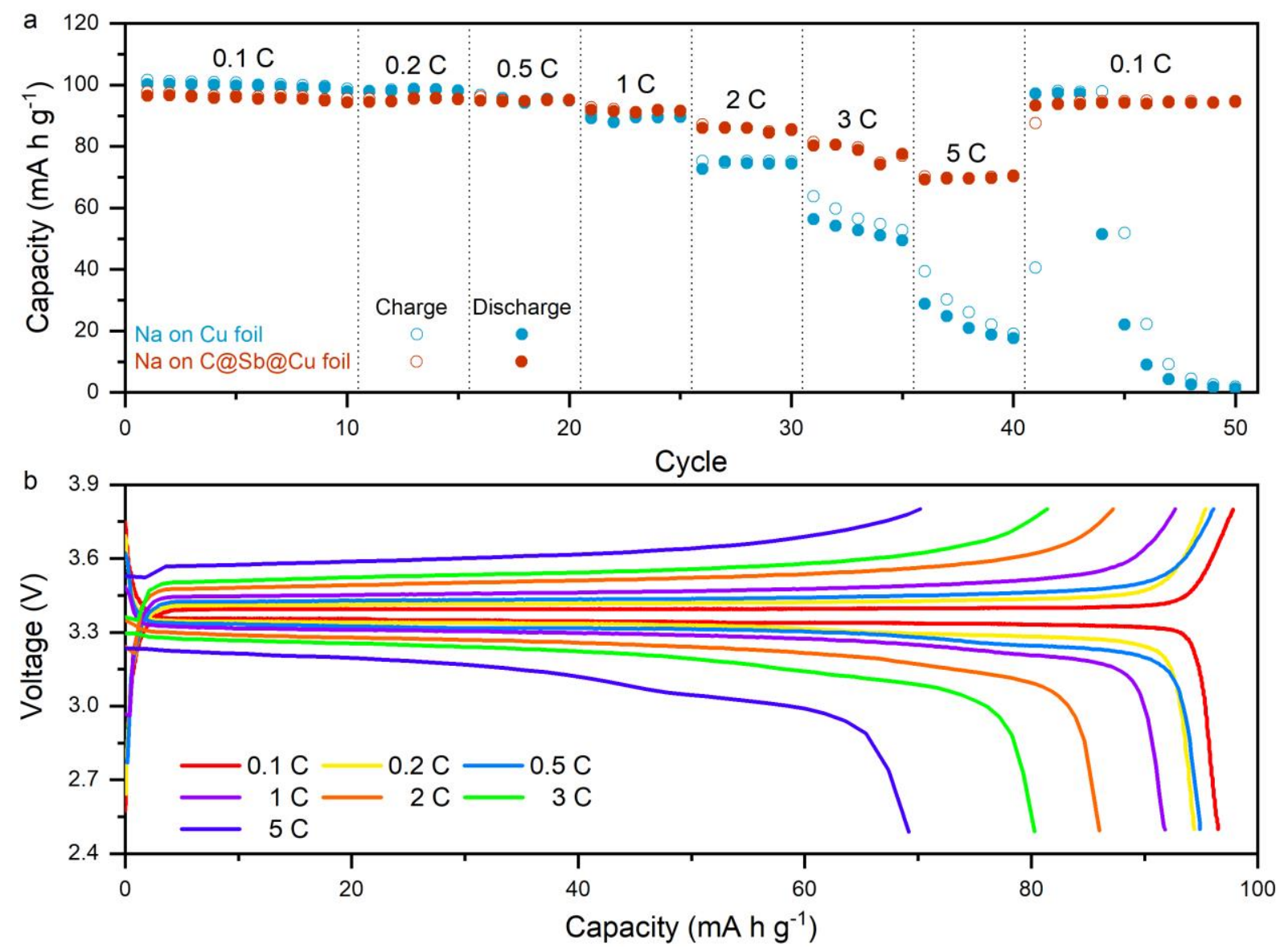

Figure S20. (a) Rate performance of $\mathrm{Na} \| \mathrm{Na}_{3} \mathrm{~V}_{2}\left(\mathrm{PO}_{4}\right)_{3}$ full cells with sodium deposited on bare or $\mathrm{C} @ \mathrm{Sb} @ \mathrm{Cu}$ foil. (b) Charge/discharge curves of $\mathrm{Na} \| \mathrm{Na}_{3} \mathrm{~V}_{2}\left(\mathrm{PO}_{4}\right)_{3}$ full cells with sodium deposited on $\mathrm{C} @ \mathrm{Sb} @ \mathrm{Cu}$ foil. The mass loading of $\mathrm{Na}_{3} \mathrm{~V}_{2}\left(\mathrm{PO}_{4}\right)_{3}$ cathode is $\sim 2 \mathrm{mg} \mathrm{cm}^{-2}$. The anode is prepared by plating $6 \mathrm{~mA} \mathrm{~h} \mathrm{~cm}{ }^{-2}$ of sodium metal on bare or $\mathrm{C} @ \mathrm{Sb} @ \mathrm{Cu}$ foil in half cell. 
Table S1. The Coulombic efficiency comparison between C@Sb nucleation buffer layer in this work and other strategies reported in the previous literatures.

\begin{tabular}{|c|c|c|c|c|c|c|c|}
\hline No. & Strategies & $\begin{array}{l}\text { Current Density } \\
\qquad\left(\mathrm{mA} \mathrm{cm}^{-2}\right)\end{array}$ & 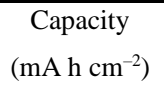 & Cycle & Time (h) & $\begin{array}{c}\text { Efficiency } \\
(\%)\end{array}$ & Ref. \\
\hline \multirow{4}{*}{1} & & 1 & 1 & 900 & 1800 & 99.75 & \multirow{4}{*}{$\begin{array}{l}\text { This } \\
\text { work }\end{array}$} \\
\hline & C@Sb nucleation buffer layer on & 1 & 4 & 738 & 5895 & 99.72 & \\
\hline & \multirow[t]{2}{*}{$\mathrm{Cu}$ current collector } & 2 & 4 & 880 & 3500 & 99.74 & \\
\hline & & 2 & 6 & 430 & 2600 & 99.37 & \\
\hline \multirow{2}{*}{2} & \multirow{2}{*}{$\mathrm{Cu} @ \mathrm{Au}$ films } & 1 & 1 & 300 & 600 & 99.8 & \multirow{2}{*}{ S3 } \\
\hline & & 2 & 1 & 300 & 300 & 99.8 & \\
\hline 3 & $\begin{array}{l}1 \mathrm{M} \mathrm{NaPF}_{6} \text { in diglyme (or } \\
\text { monoglyme or tetraglyme) }\end{array}$ & 0.5 & 1 & 300 & 1200 & 99.9 & S4 \\
\hline 4 & $\begin{array}{l}\text { nanocarbon on } \mathrm{Al} \text { current } \\
\text { collector }\end{array}$ & 0.5 & 0.25 & 1000 & 1000 & 99.8 & S5 \\
\hline \multirow{2}{*}{5} & \multirow{2}{*}{ porous $\mathrm{Al}$ current collector } & 0.5 & 0.25 & 1000 & 1000 & 99.9 & \multirow{2}{*}{ S6 } \\
\hline & & 1 & 0.5 & 1000 & 1000 & 99.8 & \\
\hline 6 & 4M NaFSI in DME & 1 & 1 & 300 & 600 & 99 & S7 \\
\hline \multirow{2}{*}{7} & $1 \mathrm{M} \mathrm{NaSO}_{3} \mathrm{CF}_{3}$ in tetraglyme & 0.5 & 1 & 300 & 1200 & 99.5 & \multirow{2}{*}{ S8 } \\
\hline & with $0.01 \mathrm{M}$ KTFSI & 1 & 1 & 280 & 560 & 98.3 & \\
\hline \multirow{2}{*}{8} & \multirow{2}{*}{$0.1 \mathrm{M} \mathrm{NaBPh}_{4}$ in DME } & 0.5 & 0.5 & 300 & 600 & 99.85 & \multirow{2}{*}{ S9 } \\
\hline & & 1 & 1 & 200 & 400 & 99.89 & \\
\hline 9 & $\begin{array}{c}\text { nitrogen \& sulfur co-doped } \\
\text { carbon nanotube paper coating on } \\
\mathrm{Na}\end{array}$ & 1 & 1 & 400 & 800 & 99.82 & $\mathrm{~S} 10$ \\
\hline 10 & $\begin{array}{c}\text { macroporous catalytic carbon } \\
\text { nanotemplates as current collector }\end{array}$ & 1 & 0.5 & $\sim 1160$ & $\sim 1160$ & 99.9 & $\mathrm{~S} 11$ \\
\hline 11 & Ag nanopaper as current collector & 1 & 1 & 50 & 100 & $\sim 100$ & $\mathrm{~S} 12$ \\
\hline \multirow[b]{2}{*}{12} & nitrogen \& sulfur co-doped & 0.5 & 1 & 600 & 2400 & 99.67 & \multirow[b]{2}{*}{ S13 } \\
\hline & $\begin{array}{c}\text { hollow carbon fibers as } \\
\text { nucleation host }\end{array}$ & 1 & 1 & 600 & 1200 & 99.52 & \\
\hline
\end{tabular}


Table S2. The performance comparison of symmetric cells between C@Sb nucleation buffer layer in this work and other strategies reported in the previous literatures.

\begin{tabular}{|c|c|c|c|c|c|c|c|}
\hline No. & Strategies & $\begin{array}{l}\text { Current Density } \\
\left(\mathrm{mA} \mathrm{cm}^{-2}\right)\end{array}$ & $\begin{array}{c}\text { Capacity } \\
\left(\mathrm{mA} \mathrm{h} \mathrm{cm}^{-2}\right)\end{array}$ & Cycle & $\begin{array}{c}\text { Time } \\
\text { (h) }\end{array}$ & $\begin{array}{c}\text { Voltage } \\
\text { hysteresis }(\mathrm{mV})\end{array}$ & Ref. \\
\hline \multirow{2}{*}{1} & C@Sb nucleation buffer layer on & 1 & 1 & 1200 & 2400 & 31 & \multirow{2}{*}{$\begin{array}{l}\text { This } \\
\text { work }\end{array}$} \\
\hline & $\mathrm{Cu}$ current collector & 1 & 2 & 297 & 1188 & 27 & \\
\hline 2 & porous $\mathrm{Al}$ current collector & 0.5 & 0.25 & 1000 & 1000 & 15.6 & S6 \\
\hline 3 & $0.1 \mathrm{M} \mathrm{NaBPh}_{4}$ in DME & 0.5 & 0.25 & 500 & 500 & 10 & S9 \\
\hline 4 & $\begin{array}{c}\text { nitrogen \& sulfur co-doped } \\
\text { carbon nanotube paper coating on } \\
\mathrm{Na}\end{array}$ & 1 & 1 & 250 & 500 & $\sim 30$ & S10 \\
\hline 5 & $\mathrm{Ag}$ nanopaper as current collector & 1 & 1 & 400 & 800 & $\sim 30$ & $\mathrm{~S} 12$ \\
\hline 6 & $\begin{array}{c}\text { nitrogen \& sulfur co-doped } \\
\text { hollow carbon fibers as } \\
\text { nucleation host }\end{array}$ & $\begin{array}{c}0.5 \\
1\end{array}$ & 1 & $\begin{array}{l}175 \\
500\end{array}$ & $\begin{array}{l}700 \\
1000\end{array}$ & $\begin{array}{r}12 \\
\sim 30\end{array}$ & S13 \\
\hline 7 & $\begin{array}{c}\text { molten } \mathrm{Na} \text { in 3D flexbile carbon } \\
\text { felt }\end{array}$ & $\begin{array}{l}1 \\
3 \\
5\end{array}$ & $\begin{array}{l}2 \\
2 \\
2\end{array}$ & $\begin{array}{l}120 \\
120 \\
130\end{array}$ & $\begin{array}{l}480 \\
160 \\
104\end{array}$ & $\begin{array}{c}20 \\
50 \\
100\end{array}$ & S14 \\
\hline 8 & $\mathrm{NaBr}-$ based SEI & $\begin{array}{c}0.25 \\
0.5 \\
1\end{array}$ & $\begin{array}{c}0.125 \\
0.25 \\
0.5\end{array}$ & $\begin{array}{l}250 \\
250 \\
250\end{array}$ & $\begin{array}{l}250 \\
250 \\
250\end{array}$ & $\begin{array}{l}\sim 110 \\
\sim 170 \\
\sim 200\end{array}$ & S15 \\
\hline 9 & molten $\mathrm{Na}$ into carbon scaffold & $\begin{array}{l}1 \\
3\end{array}$ & $\begin{array}{l}1 \\
1\end{array}$ & $\begin{array}{l}100 \\
120\end{array}$ & $\begin{array}{c}200 \\
80\end{array}$ & $\begin{array}{l}15 \\
\sim 15\end{array}$ & S16 \\
\hline 10 & $\begin{array}{c}\text { cross-linked } \mathrm{Al}_{2} \mathrm{O}_{3} \mathrm{NWs} \\
\text { membrane coated by PVdF- } \\
\text { HFP-based gel polymer } \\
\text { electrolyte }\end{array}$ & $\begin{array}{c}0.5 \\
1\end{array}$ & $\begin{array}{c}0.25 \\
0.5\end{array}$ & $\begin{array}{l}300 \\
300\end{array}$ & $\begin{array}{l}300 \\
300\end{array}$ & $\begin{array}{c}200 \\
\sim 250 \\
\sim 400\end{array}$ & S17 \\
\hline 11 & $\begin{array}{l}\text { artificial } \mathrm{Na}_{x} \mathrm{Mo}_{6} \mathrm{~S}_{8} \text { based } \\
\text { protection films }\end{array}$ & $\begin{array}{c}0.5 \\
1 \\
3\end{array}$ & $\begin{array}{l}- \\
-\end{array}$ & $\begin{array}{l}- \\
-\end{array}$ & $\begin{array}{l}1200 \\
1000 \\
400\end{array}$ & $\begin{array}{l}140 \\
160 \\
220\end{array}$ & S18 \\
\hline 12 & $\mathrm{Al}_{2} \mathrm{O}_{3}$ coating on $\mathrm{Na}$ via $\mathrm{PEALD}$ & $\begin{array}{c}0.25 \\
0.25 \\
0.5\end{array}$ & $\begin{array}{c}0.0625 \\
1 \\
1\end{array}$ & $\begin{array}{c}900 \\
50 \\
30\end{array}$ & $\begin{array}{l}450 \\
400 \\
120\end{array}$ & $\begin{array}{r}\sim 100 \\
\sim 270 \\
\sim 300\end{array}$ & S19 \\
\hline 13 & $\begin{array}{l}\text { Encapsulation of } \mathrm{Na} \text { in } \\
\text { carbonized wood }\end{array}$ & $\begin{array}{c}0.5 \\
1 \\
1\end{array}$ & $\begin{array}{c}0.25 \\
0.5 \\
1\end{array}$ & $\begin{array}{l}250 \\
250 \\
250\end{array}$ & $\begin{array}{l}250 \\
250 \\
500\end{array}$ & $\begin{array}{c}30 \\
\sim 140 \\
\sim 200\end{array}$ & S20 \\
\hline 14 & moldable Na@ rGO composites & 1 & 1 & 300 & 600 & $\sim 25$ & S21 \\
\hline 15 & $\begin{array}{l}\text { carbon-supported nitrogen- } \\
\text { anchored } \mathrm{Zn} \text { single atoms as } \\
\text { current collector }\end{array}$ & 0.5 & 0.5 & $\begin{array}{l}500 \\
150\end{array}$ & $\begin{array}{l}1000 \\
300\end{array}$ & $\begin{array}{r}56 \\
\sim 90\end{array}$ & $\mathrm{~S} 22$ \\
\hline 16 & $\begin{array}{c}\text { molten } \mathrm{Na} \text { in 3D hierarchical } \\
\text { structure containing Mg clusters }\end{array}$ & $\begin{array}{c}0.5 \\
1\end{array}$ & $\begin{array}{l}1 \\
1\end{array}$ & $\begin{array}{l}338 \\
190\end{array}$ & $\begin{array}{c}1350 \\
380\end{array}$ & $\begin{array}{c}27 \\
\sim 75\end{array}$ & S23 \\
\hline
\end{tabular}




\section{REFERENCES}

(S1) Yue, Q.; Zhang, Y.; Wang, C.; Wang, X.; Sun, Z.; Hou, X.-F.; Zhao, D.; Deng, Y. Magnetic Yolk-Shell Mesoporous Silica Microspheres with Supported Au Nanoparticles as Recyclable High-Performance Nanocatalysts. J. Mater. Chem. A 2015, 3, 4586-4594.

(S2) Wang, E.; Xiang, W.; Rajagopalan, R.; Wu, Z.; Yang, J.; Chen, M.; Zhong, B.; Dou, S. X.; Chou, S.; Guo, X.; Kang, Y.-M. Construction of 3D Pomegranate-Like $\mathrm{Na}_{3} \mathrm{~V}_{2}\left(\mathrm{PO}_{4}\right)_{3} /$ Conducting Carbon Composites for High-Power Sodium-Ion Batteries. J. Mater. Chem. A 2017, 5, 9833-9841.

(S3) Tang, S.; Qiu, Z.; Wang, X.-Y.; Gu, Y.; Zhang, X.-G.; Wang, W.-W.; Yan, J.-W.; Zheng, M.-S.; Dong, Q.-F.; Mao, B.-W. A Room-Temperature Sodium Metal Anode Enabled by a Sodiophilic Layer. Nano Energy 2018, 48, 101-106.

(S4) Seh, Z. W.; Sun, J.; Sun, Y.; Cui, Y. A Highly Reversible Room-Temperature Sodium Metal Anode. ACS Cent. Sci. 2015, 1, 449-455.

(S5) Cohn, A. P.; Muralidharan, N.; Carter, R.; Share, K.; Pint, C. L. Anode-Free Sodium Battery through in Situ Plating of Sodium Metal. Nano Lett. 2017, 17, 1296-1301.

(S6) Liu, S.; Tang, S.; Zhang, X.; Wang, A.; Yang, Q.-H.; Luo, J. Porous Al Current Collector for DendriteFree Na Metal Anodes. Nano Lett. 2017, 17, 5862-5868.

(S7) Cao, R.; Mishra, K.; Li, X.; Qian, J.; Engelhard, M. H.; Bowden, M. E.; Han, K. S.; Mueller, K. T.; Henderson, W. A.; Zhang, J.-G. Enabling Room Temperature Sodium Metal Batteries. Nano Energy 2016, 30, 825-830.

(S8) Shi, Q.; Zhong, Y.; Wu, M.; Wang, H.; Wang, H. High-Performance Sodium Metal Anodes Enabled by a Bifunctional Potassium Salt. Angew. Chem., Int. Ed. 2018, 57, 9069-9072.

(S9) Doi, K.; Yamada, Y.; Okoshi, M.; Ono, J.; Chou, C.-P.; Nakai, H.; Yamada, A. Reversible Sodium Metal Electrodes: Is Fluorine an Essential Interphasial Component? Angew. Chem., Int. Ed. 2019, 58, 80248028 .

(S10) Sun, B.; Li, P.; Zhang, J.; Wang, D.; Munroe, P.; Wang, C.; Notten, P. H. L.; Wang, G. Dendrite-Free Sodium-Metal Anodes for High-Energy Sodium-Metal Batteries. Adv. Mater. 2018, 30, 1801334.

(S11) Yoon, H. J.; Kim, N. R.; Jin, H.-J.; Yun, Y. S. Macroporous Catalytic Carbon Nanotemplates for Sodium Metal Anodes. Adv. Energy Mater. 2018, 8, 1701261.

(S12) Wang, Z.; Zhang, X.; Zhou, S.; Edstroem, K.; Stromme, M.; Nyholm, L. Lightweight, Thin, and Flexible Silver Nanopaper Electrodes for High-Capacity Dendrite-Free Sodium Metal Anodes. Adv. Funct. Mater. 2018, 28, 1804038.

(S13) Zheng, X.; Li, P.; Cao, Z.; Luo, W.; Sun, F.; Wang, Z.; Ding, B.; Wang, G.; Huang, Y. Boosting the Reversibility of Sodium Metal Anode via Heteroatom-Doped Hollow Carbon Fibers. Small 2019, 15, 1902688.

(S14) Chi, S.-S.; Qi, X.-G.; Hu, Y.-S.; Fan, L.-Z. 3D Flexible Carbon Felt Host for Highly Stable Sodium Metal Anodes. Adv. Energy Mater. 2018, 8, 1702764.

(S15) Choudhury, S.; Wei, S.; Ozhabes, Y.; Gunceler, D.; Zachman, M. J.; Tu, Z.; Shin, J. H.; Nath, P.; Agrawal, A.; Kourkoutis, L. F.; Arias, T. A.; Archer, L. A. Designing Solid-Liquid Interphases for Sodium Batteries. Nat. Commun. 2017, 8, 898.

(S16) Go, W.; Kim, M.-H.; Park, J.; Lim, C. H.; Joo, S. H.; Kim, Y.; Lee, H.-W. Nanocrevasse-Rich Carbon Fibers for Stable Lithium and Sodium Metal Anodes. Nano Lett. 2019, 19, 1504-1511.

(S17) Lei, D.; He, Y.-B.; Huang, H.; Yuan, Y.; Zhong, G.; Zhao, Q.; Hao, X.; Zhang, D.; Lai, C.; Zhang, S.; Ma, J.; Wei, Y.; Yu, Q.; Lv, W.; Yu, Y.; Li, B.; Yang, Q.-H.; Yang, Y.; Lu, J.; Kang, F. Cross-Linked Beta Alumina Nanowires with Compact Gel Polymer Electrolyte Coating for Ultra-Stable Sodium Metal Battery. Nat. Commun. 2019, 10, 4244.

(S18) Lu, K.; Gao, S.; Li, G.; Kaelin, J.; Zhang, Z.; Cheng, Y. Regulating Interfacial Na-Ion Flux Via Artificial Layers with Fast Ionic Conductivity for Stable and High-Rate Na Metal Batteries. ACS Mater. Lett. 2019, 1, 303-309.

(S19) Luo, W.; Lin, C.-F.; Zhao, O.; Noked, M.; Zhang, Y.; Rubloff, G. W.; Hu, L. Ultrathin Surface Coating Enables the Stable Sodium Metal Anode. Adv. Energy Mater. 2017, 7, 1601526. 
(S20) Luo, W.; Zhang, Y.; Xu, S.; Dai, J.; Hitz, E.; Li, Y.; Yang, C.; Chen, C.; Liu, B.; Hu, L. Encapsulation of Metallic $\mathrm{Na}$ in an Electrically Conductive Host with Porous Channels as a Highly Stable Na Metal Anode. Nano Lett. 2017, 17, 3792-3797.

(S21) Wang, A.; Hu, X.; Tang, H.; Zhang, C.; Liu, S.; Yang, Y.-W.; Yang, Q.-H.; Luo, J. Processable and Moldable Sodium-Metal Anodes. Angew. Chem., Int. Ed. 2017, 56, 11921-11926.

(S22) Yang, T.; Qian, T.; Sun, Y.; Zhong, J.; Rosei, F.; Yan, C. Mega High Utilization of Sodium Metal Anodes Enabled by Single Zinc Atom Sites. Nano Lett. 2019, 19, 7827-7835.

(S23) Zhu, M.; Li, S.; Li, B.; Gong, Y.; Du, Z.; Yang, S. Homogeneous Guiding Deposition of Sodium through Main Group Ii Metals toward Dendrite-Free Sodium Anodes. Sci. Adv. 2019, 5, eaau6264. 